\title{
Lesion-Induced Sprouting of Commissural/Associational Axons and Induction of GAP-43 mRNA in Hilar and CA3 Pyramidal Neurons in the Hippocampus Are Diminished in Aged Rats
}

\author{
P. Elyse Schauwecker, Heng-Wei Cheng, Rose Marie P. Serquinia, Nozomu Mori, and Thomas H. McNeill \\ Department of Biological Sciences and Division of Neurogerontology, Andrus Gerontology Center, University of \\ Southern California, Los Angeles, California 90089-0191
}

\begin{abstract}
Removal of synaptic connections following a partial deafferentation lesion results in a sprouting of remaining afferents that terminate near the denervated area. However, while the ability to form new synapses in response to injury has been reported in both young and aged rats, previous studies have suggested that the injury-induced response in the hippocampus of aged rats may be delayed and/or not as extensive as compared to young adults. Given that growth associated proteins are central for the regulation of neurite outgrowth during both development and regeneration, we were interested in determining if the magnitude and time course of the sprouting response of hippocampal neurons to deafferentation might correlate with induction of growth associated proteins and whether these parameters could be modulated with age. For our studies we used the Holmes fiber stain to determine the expansion of the C/A fiber plexus following denervation and compared the time course of the sprouting response with that observed by in situ hybridization for the neurite outgrowth proteins, growth associated protein-43 (GAP-43), superior cervical ganglion-10 (SCG-10), and neurofilament-68 (NF-68) at various time points after the lesion for each age group. We found that the commissural/associational (C/A) fiber plexus expanded by $45 \%$ in young adult rats at 30 and $45 \mathrm{~d}$ postlesion and was accompanied by a significant increase in expression of GAP-43 mRNA in both ipsilateral and contralateral hilar and CA3 pyramidal neurons, the cell bodies of origin for the C/A pathway. In contrast, a dampened sprouting response was observed in aged rats at all time points postlesion and coincided with a lack of induction of any of the growth-associated proteins. These results suggest that GAP-43 is involved in outgrowth of C/A axons in the hippocampus in response to a partial deafferentation lesion. However, factors that stimulate neurite outgrowth and upregulate GAP-43 mRNA in response to a partial deafferentation lesion diminish with age.
\end{abstract}

[Key words: hippocampus, dentate gyrus, reactive synaptogenesis, deafferentation, growth-associated proteins, sprouting]

\footnotetext{
Received Aug. 25, 1994; accepted Sept. 28, 1994.

This work supported by USPHS Grants AG-9793, NS 30426, and the Multidisciplinary Training Grant in Gerontology $\Lambda$ G00037.

Correspondence should be addressed to Thomas H. McNeill, Andrus Gerontology Center, University of Southern California, Los Angeles, CA 900890191

Copyright (C) 1995 Society for Neuroscience $0270-6474 / 95 / 152462-09 \$ 05.00 / 0$
}

The development of the mammalian nervous system involves the formation of complex ncuroanatomical networks achieved through the differential expression of gene products which direct cell migration, neurite outgrowth and new synapse formation. In addition, it is known that neurons in many regions of the adult brain retain their ability to remodel their synaptic circuitry in response to changes in their cellular environment and that the ability of the nervous system to adapt to various cellular stimuli is critical for reestablishing a synaptic circuitry that can lead to functional recovery in response to brain injury (Cotman and Anderson, 1988; Coleman et al., 1990). In contrast, it has been suggested that an impaired or aberrant adaptive response, albeit part of natural aging or a disease process, may contribute to the progression of neuropathological deficits typically described in age-associated neurodegenerative diseases of the CNS (reviewed in Geddes et al., 1985; Represa et al., 1988; Flood and Coleman, 1991).

Given that growth associated proteins (GAPs) are central for the regulation of neurite outgrowth during both development and regeneration, we characterized changes in the time course of gene expression of GAPs that can serve as markers for evaluating age-related changes that occur in the brain in response to neuronal deafferentation. In this study, we examined changes in the expression of three GAP mRNAs, previously reported to be involved in neurite outgrowth during both development and regeneration. First, GAP-43 is an axonally transported phosphoprotein that is prominent in growth cones and its phosphorylation by protein kinase $\mathrm{C}$ has been implicated in long term potentiation (Lovinger et al., 1986; Linden et al., 1988), signal transduction (Van Hooff et al., 1988), and neurotransmitter release (Nairn and Shenolikar, 1992). Second, SCG-10 is a newly described neuron specific protein involved in neurite outgrowth. SCG-10 was first isolated from developing neurons of sympathoadrenal lineage and is upregulated in developing neural crest neurons induced by NGF (Stein et al., 1988). Third, NF-68 is one part of a triplet polypeptide thought to play an important role in the reorganization of the axonal cytoskeleton during neurite growth (Hoffman, 1987, 1989). It is a neuron specific protein found in both axons and dendrites, unlike many other cytoskeletal proteins, which are found in both neurons and glia (Kleinman et al., 1990).

We hypothesize that in the adult hippocampus GAPs play an important regulatory role during ncuritc outgrowth in response to brain injury and that age-related changes in the time course or magnitude of a hippocampal neurons sprouting response may be correlated with changes in GAP message. Specifically, we 

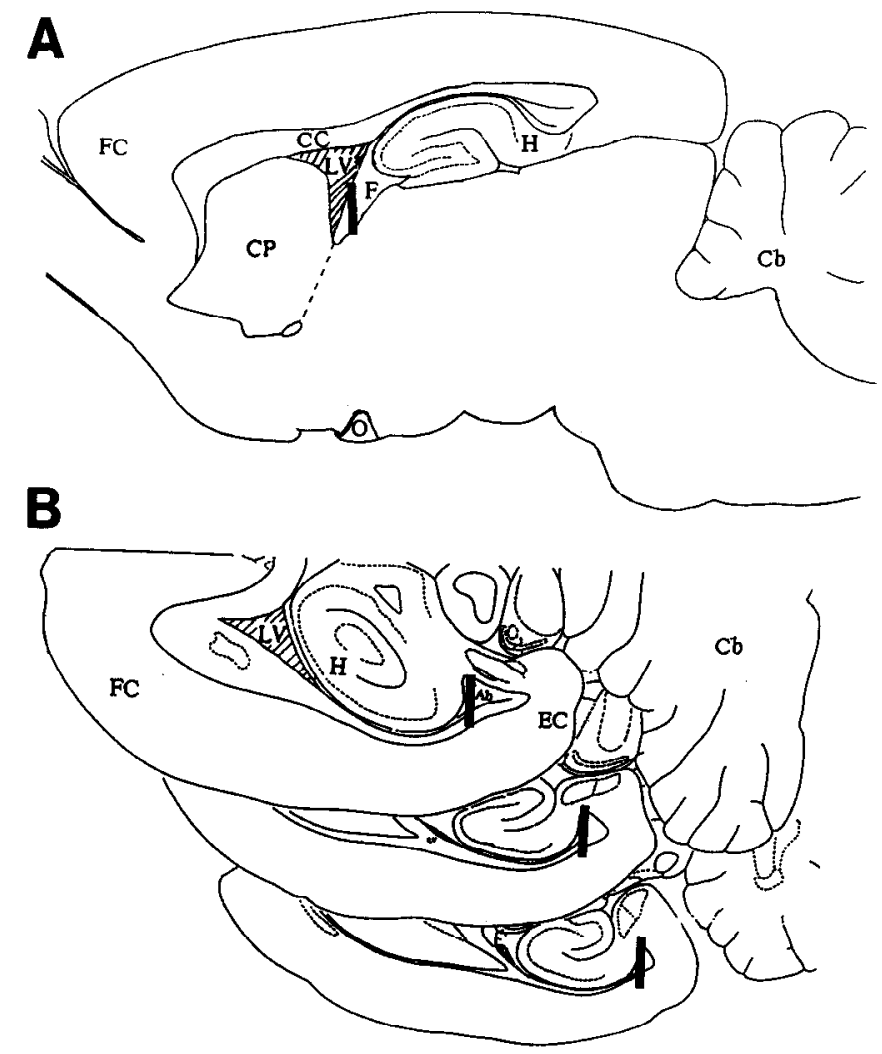

Figure 1. Schematic diagrams of the FF $(A)$ and EC lesions $(B) . A$ is a drawing of the rat brain sectioned in the sagittal plane. The blackened bar indicates the anatomical level of the FF transection made by the knife cut. $B$ is a composite of three diagrams of the hemisected rat brain viewed in the horizontal plane. The blackened bar indicates the location of the angular bundle transection at various anatomical levels of the hippocampus. Schematic drawings were prepared from Paxinos and Watson (1986) and the location of the lesions was verified from Nisslstained sections. Abbreviations used include $A b$, angular bundle; $C b$, cerebellum; $C C$, corpus callosum; $C P$, caudate putamen; $E C$, entorhinal cortex; $F$, fimbria; $F C$, frontal cortex; $H$, hippocampus; $L V$, lateral ventricle; $O$, optic tract.

examined the effect of age on the changes in mRNA levels for GAP-43, SCG-10, and NF-68 in neurons of the C/A pathway of the hippocampus following a combined lesion of the entorhinal cortex and fimbria fornix (EC/FF) and used the Holmes fiber stain to assess the corresponding sprouting response of C/A axons into the deafferented hippocampus. We report that the sprouting of C/A axons into the deafferented dentate gyrus temporally parallels the upregulation of GAP-43 mRNA but not SCG-10 or NF-68 mRNA in hilar and CA3 pyramidal neurons in young adult rats. By comparison, the dampened sprouting response of C/A fibers in aged rats is associated with an absence of GAP-43 mRNA induction.

\section{Materials and Methods}

Lesions. Male Fischer-344 rats, 3 months or 24 months of age, were deeply anesthetized with pentobarbital $(50 \mathrm{mg} / \mathrm{kg}$, i.p.) and were placed in a stereotaxic apparatus. Stereotaxic lesions of the EC/FF were performed with an extendable Scouten knife (Kopf Inc., Tujunga, CA). For FF transections, a hole was drilled in the cranium $1.5 \mathrm{~mm}$ posterior to bregma and $2.0 \mathrm{~mm}$ lateral to the midline. The retracted knife was lowered $5.0 \mathrm{~mm}$ below the dura, and the wire blade was extended 2.0 $\mathrm{mm}$ toward the midline. Transection of the FF was made by raising the blade $4.0 \mathrm{~mm}$, making sure the extended knife did not cross the midline and damage the contralateral fimbria (Figs. $1 A, 2 A, B$ ). Subsequently, the wire knife was retracted and the holder was removed. For lesions of the perforant pathway, a knife cut was made that transected the angular bundle, disrupting the projection fibers from the entorhinal cortex. Specifically, a burr hole was drilled $0.5 \mathrm{~mm}$ anterior to lambda and 5.3 $\mathrm{mm}$ lateral to the midline. The retracted knife was lowered $5.0 \mathrm{~mm}$ below the dura, and the wire blade was extended $1.0 \mathrm{~mm}$ towards the midline. In order to lesion the angular bundle, the wire blade was raised $4.0 \mathrm{~mm}$ and then retracted (Fig. $1 B$ ). Wounds were sutured and animals remained under standard housing conditions until the end of the experiment.

As reported previously, transection of the FF, using the protocol described above, results in a loss of cholinesterase staining and dopamine$\beta$-hydroxylase immunoreactivity from the dentate gyrus molecular layer (Schauwecker and McNeill, 1995). In addition, complete transection of the angular bundle, which removes fiber projections originating from both the lateral and medial EC, was confirmed by examination of cresyl violet stained sections cut in the horizontal plane through the hippocampus (Fig. $2 C, D$ ). In all animals examined, no damage to the hippocampus proper or area dentata was observed.

Tissue processing for Holmes stain. In the dentate gyrus, the Holmes silver stain was used to assess changes in the innervation from the $\mathrm{C} / \mathrm{A}$ pathway. Animals were deeply anesthetized with pentobarbital $(50 \mathrm{mg} /$ $\mathrm{kg}$, i.p.) and perfused through the heart with saline followed by a solution of $4 \%$ paraformaldehyde in phosphate buffer $(\mathrm{pH} 7.4)$. Brains were removed, postfixed overnight in the same fixative, and then immersed in $30 \%$ sucrose for $2 \mathrm{~d}$. Coronal sections were cut from the dorsal hippocampus at $30 \mu \mathrm{m}$ in thickness on a freezing microtome and every third section was stained with the Holmes fiber stain following the method outlined by Sheehan and Hrapchak (1980). Briefly, sections were hydrated, incubated in $1 \%$ silver nitrate in the dark for $2 \mathrm{hr}$, and then impregnated in a solution containing $9 \%$ boric acid buffer, $8 \%$ borax buffer, $1 \%$ silver nitrate, and $10 \%$ pyridine at $37^{\circ} \mathrm{C}$ overnight, followed by immersion in a reducing solution containing $1 \%$ hydroquinone and $10 \%$ sodium sulfate. Sections were then incubated in $0.2 \%$ gold chloride, which intensifies the fiber staining, for $6 \mathrm{~min}, 2 \%$ oxalic acid for $8 \mathrm{~min}$, and $5 \%$ sodium thiosulfate for $5 \mathrm{~min}$. Sections were then dehydrated and coverslipped.

We examined changes in the C/A pathway at $14,30,45$, and $60 \mathrm{~d}$ postlesion in both age groups ( $n=4$ per time point for each age group) and compared these findings with data taken from intact control rats $(n$ $=4$ ). These times were chosen based on previous morphological studies which examined the time course of reactive synaptogenesis in the partially deafferented hippocampus (reviewed in Cotman and Nadler, 1978; Cotman et al., 1981; Cotman and Anderson, 1988) and spanned the time required for the reinnervation of the lesioned hippocampus following a unilateral EC lesion (Lynch et al., 1972; Scheff et al., 1978; Caceres and Steward, 1983).

Quantitative analysis of the C/A fiber plexus. The expansion of the C/A fiber plexus was analyzed using brain sections stained by the Holmes fiber stain and analyzed following the methods of Scheff and coworkers $(1980,1983)$. As in their studies, two days prior to sacrifice, the contralateral EC was lesioned (knife cut) in order to facilitate the measurement of the boundary of the C/A fiber plexus ipsilateral to the primary lesion and the width of the fiber plexus ipsilateral to the lesion was compared to both the width of the fiber plexus in the contralateral hippocampus as well as intact controls.

Camera lucida drawings $(20 \times)$ from the dorsal blade of the dentate gyrus were made from every third section of the dentate gyrus and for each section, and the absolute width of the fiber plexus was determined at three points perpendicular to the granule cell layer on both the lesioned and control sides of the hippocampus. Reactive sprouting of the fiber plexus was expressed as the ratio of the width of the C/A fiber plexus on the side ipsilateral to the primary lesion divided by the width of the fiber plexus on the contralateral side. Data were also compared with data obtained from intact control rats. Age and postlesion time effect were analyzed using multivariate analysis and the Newman-Keuls post hoc test using the interactive statistical software $\mathrm{CRUNCH}$ (Crunch Software Corp., Oakland, CA) with $N$ equal to the number of rats in each age group.

Preparation of riboprobes. All cDNA probes used in the present study were transcribed in the presence of ${ }^{35} \mathrm{~S}-\mathrm{UTP}(1300 \mathrm{Ci} / \mathrm{mmol}$; Du Pont, Wilmington, DE). GAP-43 cRNAs were transcribed from a pGEM4 plasmid containing a 1121 base pair (bp) rat GAP-43 insert (kindly provided by Dr. M. Fishman). SCG-10 specific riboprohes were transcribed from a SP65 plasmid containing a 2000 bp rat SCG-10 insert 

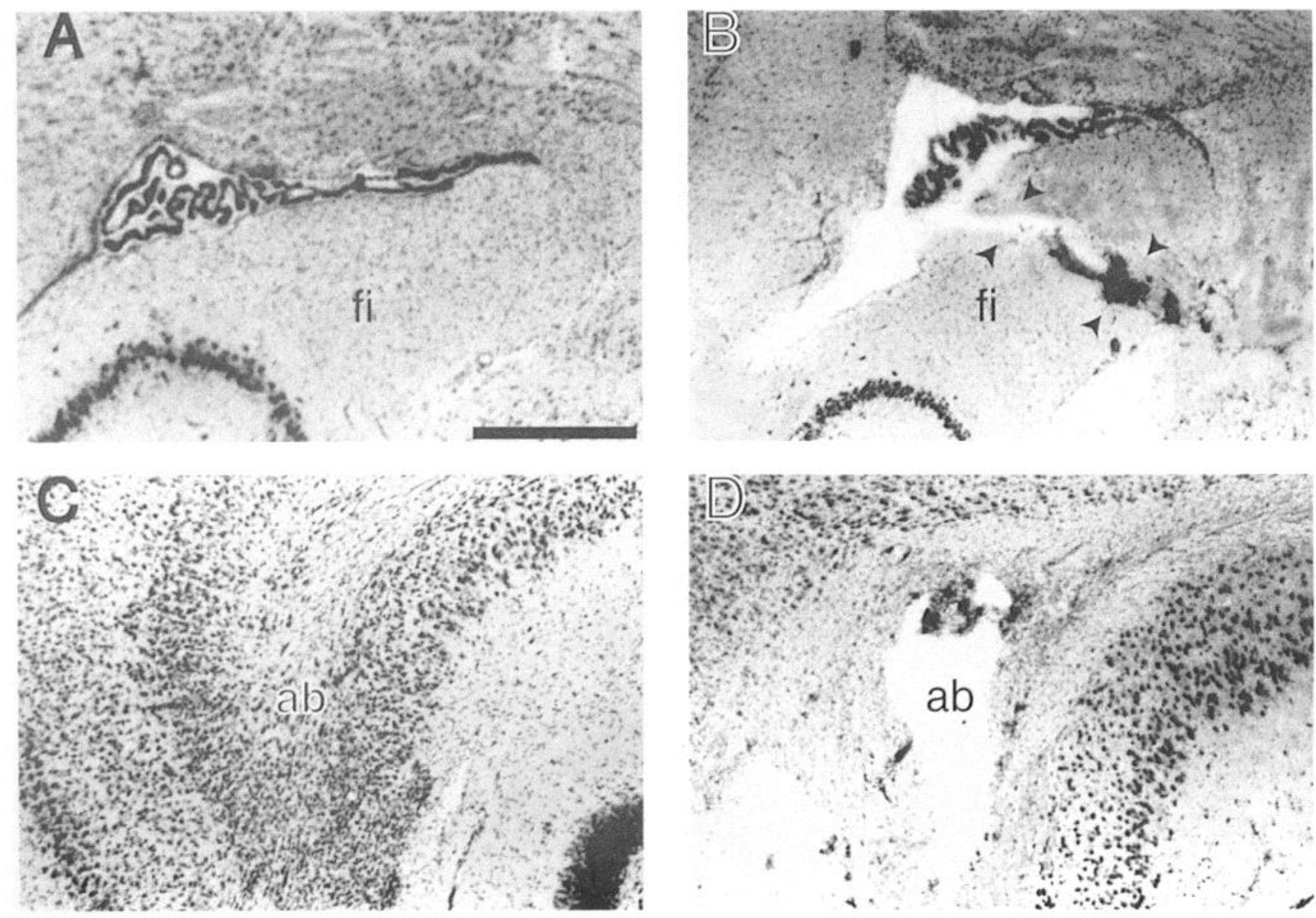

Figure 2. Photomicrographs of Nissl-stained tissue sections documenting the extent of the FF and the EC lesion. $A$ is a Nissl-stained sagittal section of the hippocampus from a control rat showing the intact fimbria $(f i) . B$ depicts the transected fimbria rostral to the hippocampus following a unilateral FF transection. $C$ is a Nissl-stained horizontal section of the hippocampus from a control rat showing the intact angular bundle. $D$ illustrates the disruption of the angular bundle $(a b)$ following the knife-cut lesion. Scale bar, $200 \mu \mathrm{m}$.

(kindly provided by Dr. D. Anderson), while NF-68 riboprobes were transcribed from a pGEM plasmid containing a 900 bp rat NF-68 insert (kindly provided by Dr. N. Cowan).

In situ hybridization. We examined changes in message by in situ hybridization at four time points postlesion and compared these findings with data taken from intact controls. Rats $(n=5$ per age group at each time point) were decapitated at $14,20,30$, and $45 \mathrm{~d}$ postlesion and the brains were immediately frozen in isopentane at $-20^{\circ} \mathrm{C}$. Sections $(14$ $\mu \mathrm{m}$ ) were cut on a cryostat (Microm, Thornwood, NY) and thaw mounted onto poly-L-lysine coated slides, and stored at $-70^{\circ} \mathrm{C}$. After fixation in $4 \%$ paraformaldehyde in phosphate-buffered saline (PBS) for $30 \mathrm{~min}$, sections were hybridized at $50^{\circ} \mathrm{C}$ for $3 \mathrm{hr}$ in a humidified chamber with $10 \mu \mathrm{l}$ hybridization solution per section $(50 \%$ formamide, $4 \times$ sodium chloride-sodium citrate buffer (SSC), $5 \times$ Denhardt's, $1 \%$ sodium dodecyl sulfate (SDS), $10 \%$ dextran sulfate, $250 \mu \mathrm{g} / \mathrm{ml}$ tRNA, 25 $\mu \mathrm{g} / \mathrm{ml}$ poly A, $25 \mu \mathrm{g} / \mathrm{ml}$ poly C, and $0.1 \mathrm{M}$ dithiothreitol (DTT) containing $0.3 \mathrm{ng} / \mu \mathrm{l} / \mathrm{kb}$ riboprobe. Sections were subsequently rinsed, incubated in $20 \mu \mathrm{g} / \mathrm{ml} \mathrm{RNase} \mathrm{A}$ at $37^{\circ} \mathrm{C}$ for $30 \mathrm{~min}$, washed in $50 \%$ formamide, $0.5 \mathrm{M} \mathrm{NaCl}$, and $50 \mathrm{~mm}$ sodium phosphate $(\mathrm{pH} 7.0)$ containing $1 \% \beta$-mercaptoethanol at $60^{\circ} \mathrm{C}$ for $1 \mathrm{hr}$, and then washed at $37^{\circ} \mathrm{C}$ in $1 \times \mathrm{SSC}$ with $1 \% \beta$-mercaptoethanol overnight. Sections were dehydrated through graded alcohols and air dried. Sections and ${ }^{14} \mathrm{C}$ standards (Kodak) were exposed to $\mathrm{x}$-ray film (Kodak, Rochester, NY) for $3-5 \mathrm{~d}$. The labelling intensity for each probe was determined by optical density measurement from autoradiograms corresponding to coronal sections of the brain using an image processing and analysis system (BQ MEG IV system, Nashville, TN). The optical density values were calculated after subtraction of the film background density. The optical density was measured bilaterally with no less than 10 measurements for each probe, brain, and brain area, respectively. Values given represent the means of at least five different animals for each experimental time point and age. The results were assessed statistically by a one-way ANOVA, and intergroup differences were analyzed by Newman-Keuls post hoc test.

Following film autoradiography, sections were processed for emulsion autoradiography. Slides were dipped in Kodak NTB-2 photo-emulsion (diluted 1:1 in $600 \mathrm{mM}$ ammonium acetate) and exposed in the dark for $3-5$ weeks at $4^{\circ} \mathrm{C}$. Slides were developed in D-19 (Kodak, Rochester, NY) at $15^{\circ} \mathrm{C}$ for $4 \mathrm{~min}$, fixed for $6 \mathrm{~min}$, and counterstained with cresyl violet. Quantification of grain density over individual cell bodies was assessed using a computer enhanced video densitometer (Southern Micro Instruments, Atlanta, GA). Labeling was considered specific when grain accumulations over cells with a large nucleus exceeded five times the background value. Cells containing high grain density were selected and the number of grains within this field were counted with a $100 \times$ oil immersion objective. At least three representative sections from five animals for each age and time point were processed for analysis. Results were assessed statistically using oneway ANOVA, and intergroup differences were analyzed by NewmanKeuls post hoc test.

\section{Results}

\section{Age comparison of C/A fiber outgrowth}

Camera lucida drawings of the C/A fiber plexus were made along the dorsal blade of the dentate gyrus at a septal level of the hippocampus at $14,30,45$, and $60 \mathrm{~d}$ after an EC/FF lesion in young adult or aged rats and compared to intact controls. For each drawing, the width of the C/A fiber plexus was determined 


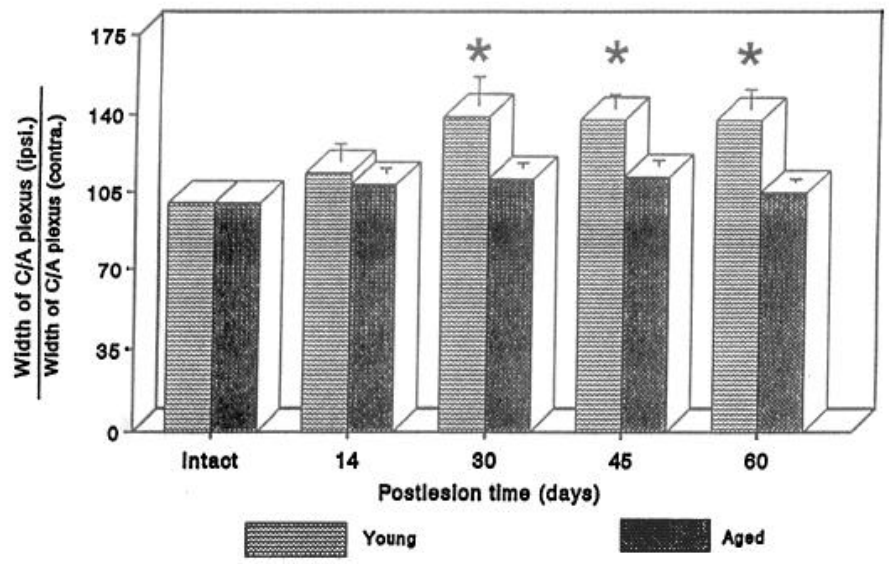

Figure 3. Effect of aging on axonal sprouting from the C/A fiber plexus following a combined EC/FF lesion. The C/A width in young animals was significantly greater $(P<0.0001)$ than aged animals at 30 , 45 , and $60 \mathrm{~d}$ postlesion. Values represent means \pm SEM.

and reactive sprouting of the fiber plexus was expressed as the ratio of the width of the C/A fiber plexus on the side ipsilateral to the primary lesion divided by the width of the fiber plexus on the contralateral side.

Qualitatively, axons of the C/A pathway formed a dense band of fibers that were oriented parallel to the dorsal blade of the dentate gyrus in both young and aged rats regardless of whether they received a lesion. In addition, there was not an obvious difference in the density of the fiber plexus between young and aged intact rats. However, following the combined EC/FF lesion, the density of the C/A fiber plexus in young rats was consistently greater than that observed in aged rats with an EC/FF lesion.

As observed in Figure 3, we found that there was a significant age effect with respect to the C/A sprouting response following the combined EC/FF lesion. At 30, 45, and $60 \mathrm{~d}$ postlesion, there was a significant increase $(45 \%)$ in the width of the C/A fiber plexus compared to the width of the plexus in the contralateral hippocampus. The increase in the width of the fiber plexus was present at $30 \mathrm{~d}$ postlesion and remained increased at $60 \mathrm{~d}$ postlesion $(F=38.995 ; P<0.0001)$. By comparison, little sprouting (10\% increase) was observed in aged rats following the $\mathrm{EC} /$ FF lesion. While sprouting from the C/A fiber plexus increased in young rats, the sprouting response in aged rats was not significantly different from intact controls (Fig. 4).

\section{Expression of growth-associated proteins}

As shown in Figure 5, the distribution of mRNAs for GAP-43, SCG-10, and NF-68 in intact rats was identical to that reported previously (Benowitz et al., 1988; Kleiman et al., 1990; Meberg and Routtenberg, 1991; Kruger et al., 1992; Kruger et al., 1993; Himi et al., 1994), and there were no age-related changes with regard to expression or distribution of any of the GAP mRNAs present in intact rats. For adult rats, the heaviest label of GAP43 mRNA was restricted to the cell soma of hilar and CA3 pyramidal neurons of the hippocampus while pyramidal cells in CA1 exhibited light to moderate label. In contrast, no label was present in the granule cells of the dentate gyrus. For SCG-10 mRNA, expression was evident in pyramidal cell layers located in all subfields of Ammon's horn (CA1-CA3), in hilar neurons, and in granule cells of the dentate gyrus. CA3 pyramidal and hilar cells showed the most intense hybridization, however, in
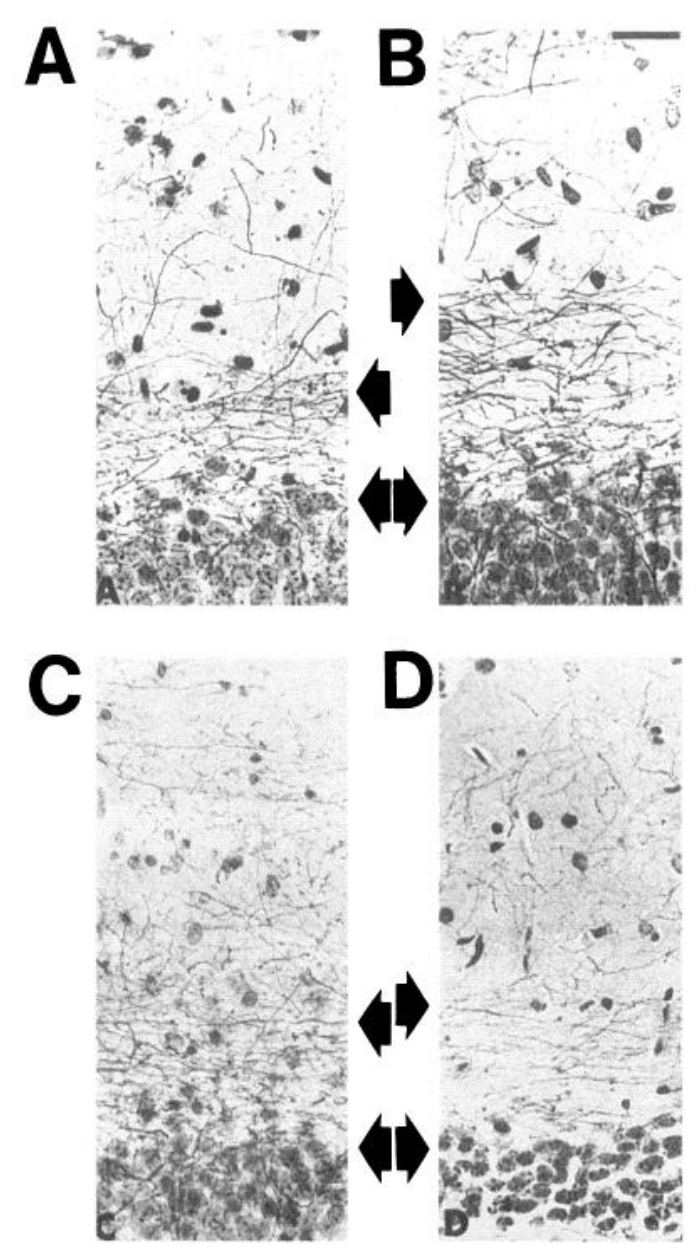

Figure 4. Photomicrograph comparing the expansion of the C/A fiber plexus using the Holmes fiber stain. $A$ demonstrates the staining pattern in a young adult intact animal, while $B$ represents enhanced outgrowth $30 \mathrm{~d}$ following the combined lesion. $C$ demonstrates the staining pattern in an old intact animal, while $D$ represents a dampened sprouting response $30 \mathrm{~d}$ following the combined lesion. Scale bar, $20 \mu \mathrm{m}$.

contrast to GAP-43 mRNA expression, the signal in CA3 pyramidal cells was not sufficiently greater than that observed in CA2 pyramidal cells to allow these two regions to be distinguished. For comparison, NF-68 mRNA distribution in intact rats was similar to that seen for SCG-10 mRNA expression. Levels of hybridization were strongest in CA3 pyramidal and hilar cells with moderate expression in CA1 and CA2 subfields of Ammon's horn and granule cells of the dentate gyrus.

Following an EC/FF lesion in young adult rats, a significant increase (two- to threefold) in GAP-43 mRNA expression was observed in both contralateral and ipsilateral hilar and CA3 pyramidal cells at $30 \mathrm{~d}$ postlesion and a six- to sevenfold increase was observed bilaterally in CA3 pyramidal and hilar cells at 45 $\mathrm{d}$ postlesion (Figs. 6, 7). In contrast, no alterations in either SCG-10 or NF-68 mRNA expression were observed in any hippocampal region at any time point after the combined lesion in young adult rats. In addition, no changes in expression of GAP43 mRNA were observed in any other subgroup of neurons of the hippocampus.

In comparison, in aged rats no changes in GAP-43, SCG-10, or NF-68 mRNA expression in the ipsilateral or contralateral hippocampus were observed between 14 and $45 \mathrm{~d}$ following the 

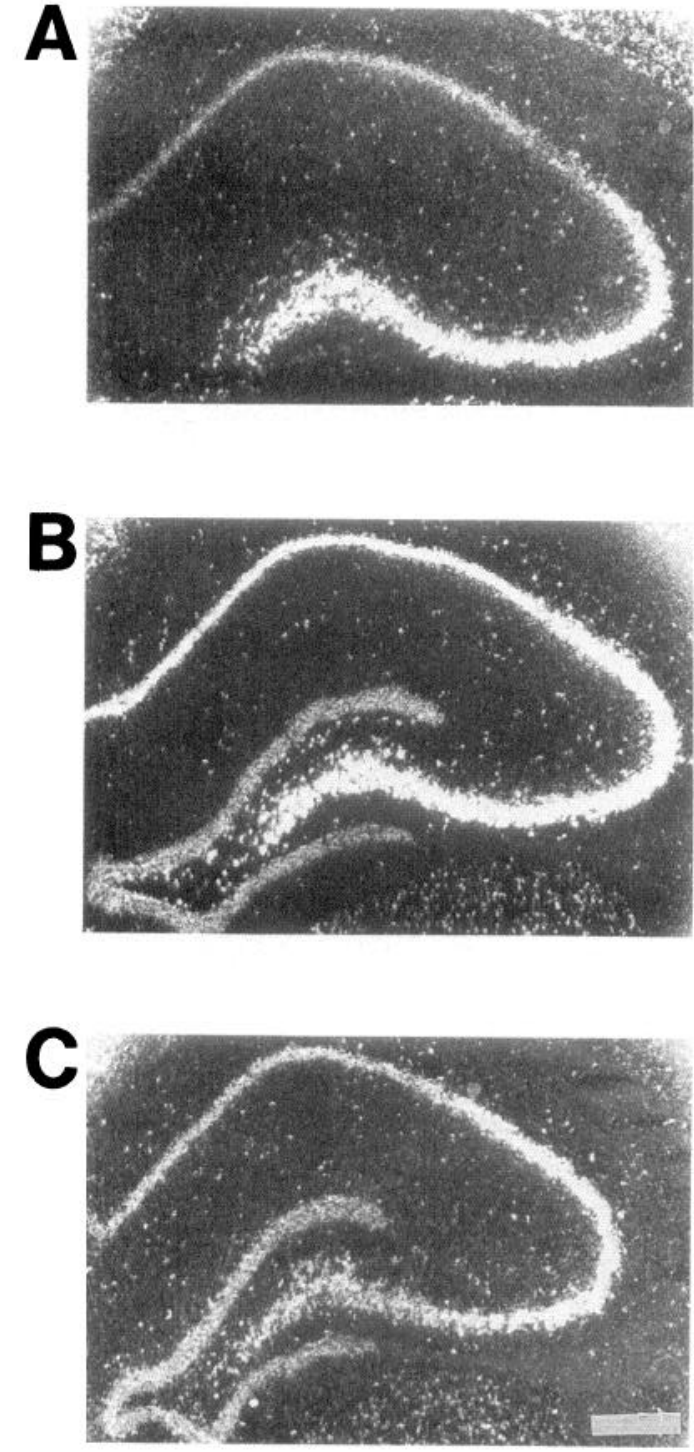

Figure 5. Distribution of GAP-43 (A), SCG-10 (B), and NF-68 (C) mRNA expression in coronal sections of young ( 3 month old) intact F-344 rats. Scale bar, $50 \mu \mathrm{m}$.

combined EC/FF lesion. In addition, GAP expression in both ipsilateral and contralateral hippocampus was similar to what was observed in intact animals (Fig. 7). Furthermore, no agerelated alterations in GAP-43 mRNA expression and/or distribution were observed between young and old intact animals.

\section{Discussion}

The results of this study demonstrate that the sprouting response of C/A axons into the middle molecular layer of the dentate gyrus following a deafferentation lesion involving both the EC and $\mathrm{FF}$ is dampened in aged rats and extends previous studies which have reported that neurons of the C/A pathway exhibit a sprouting response that decreases with age following a unilateral lesion of the EC alone. Previous studies have reported that in rats younger than postnatal day 7, C/A axons can sprout to occupy nearly the entire molecular layer of the dentate gyrus following a lesion of the EC which removes over $85 \%$ of the afferent input to the outer molecular layer of the dentate gyrus (Lynch et al., 1973). By comparison, in adult rats, C/A fibers in
A
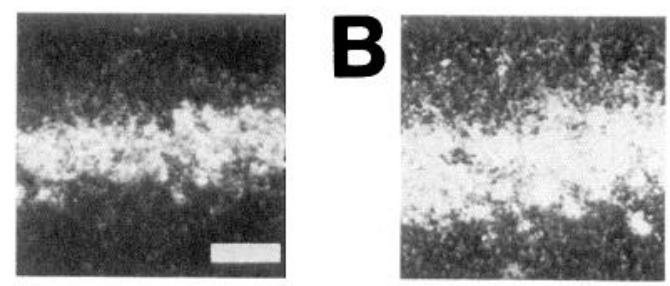

C
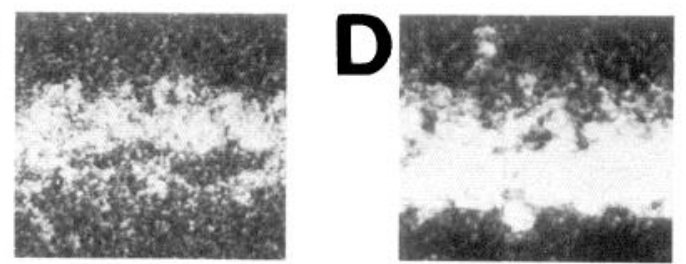

Figure 6. Distribution of grains over neuronal cell bodies by GAP-43 mRNA by in situ dark-field emulsion autoradiography in CA3 pyramidal cells in $(A, C)$ intact and $(B, D) 45 \mathrm{~d}$ post-EC/FF lesioned animals. Note that the increase in GAP-43 mRNA was observed in both ipsilateral $(C)$ and contralateral $(D)$ sides of the lesioned animal. Scale bar, $20 \mu \mathrm{m}$.

the inner molecular layer extend only partway into the middle molecular layer following an EC lesion, and the sprouting response of C/A axons following an EC lesion is absent in aged rats (Lynch et al., 1973, 1976, 1977; Nadler et al., 1977; Scheff et al., 1978; Cotman and Scheff, 1979; Gall and Lynch, 1981). Our findings extend previous studies on the hippocampal response to a unilateral EC lesion and suggest that the extent of sprouting of C/A axons following a deafferentation lesion is agedependent and does not necessarily depend on the type of lesion involved. In addition, our data suggest that factors that regulate events that stimulate neurite outgrowth in the hippocampus following brain injury decrease with age; however, the identification of specific factors that regulate sprouting of C/A axons are currently unknown.

Our finding that increased expression of GAP-43 mRNA temporally correlates with the expansion of the C/A fiber plexus into the middle molecular layer of the dentate gyrus provides further evidence that GAP-43 is involved in the regulation of neurite outgrowth of C/A axons in the adult brain following injury. Previous studies have demonstrated that GAP-43, also known as B-50 (Nielander et al., 1987), GAP-48, F1 (Rosenthal et al., 1987), pp46 (Meiri et al., 1986), and P57 (Cimler et al., 1987), is a fast axonally transported phosphoprotein that is important in axon growth (Benowitz and Routtenberg, 1987; Skene, 1989; Stewart et al., 1993) and its phosphorylation by protein kinase $\mathrm{C}$ has been implicated in long term potentiation, signal transduction, and neurotransmitter release (Linden et al., 1988; Vanhooff et al., 1988; Nairn and Shenolikar, 1992; Swope et al., 1992). GAP-43 protein content and mRNA expression are upregulated in both the PNS (Forman and Berenberg, 1978) and CNS (Skene and Willard, 1981; Benowitz and Schmidt, 1987) following axotomy and levels of GAP-43 protein increase dramatically in the dentate gyrus following an EC lesion, coincident with the expansion of the C/A fiber plexus into the middle molecular layer of the dentate gyrus (Benowitz et al., 1990). In addition, previous studies have found that there is a twofold increase in the transport of newly synthesized GAP-43 to the 
YOUNG
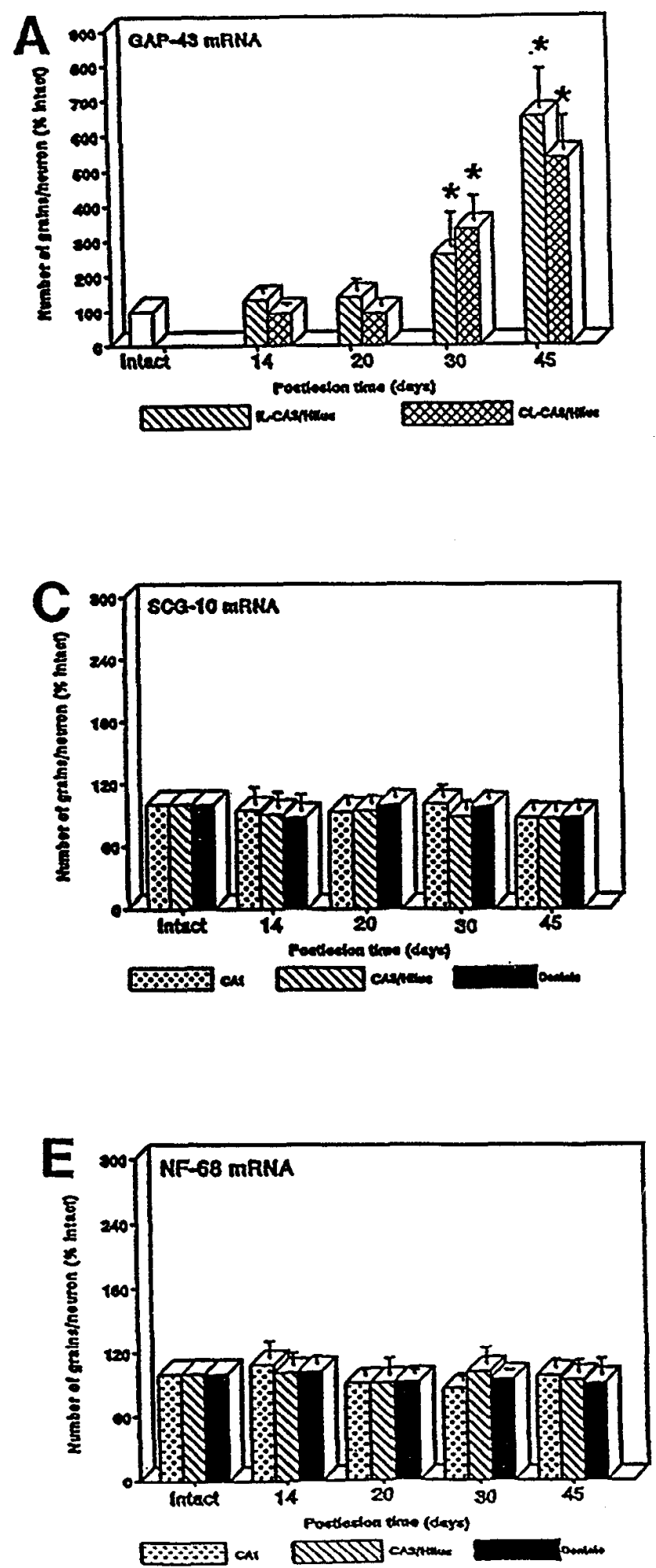

AGED
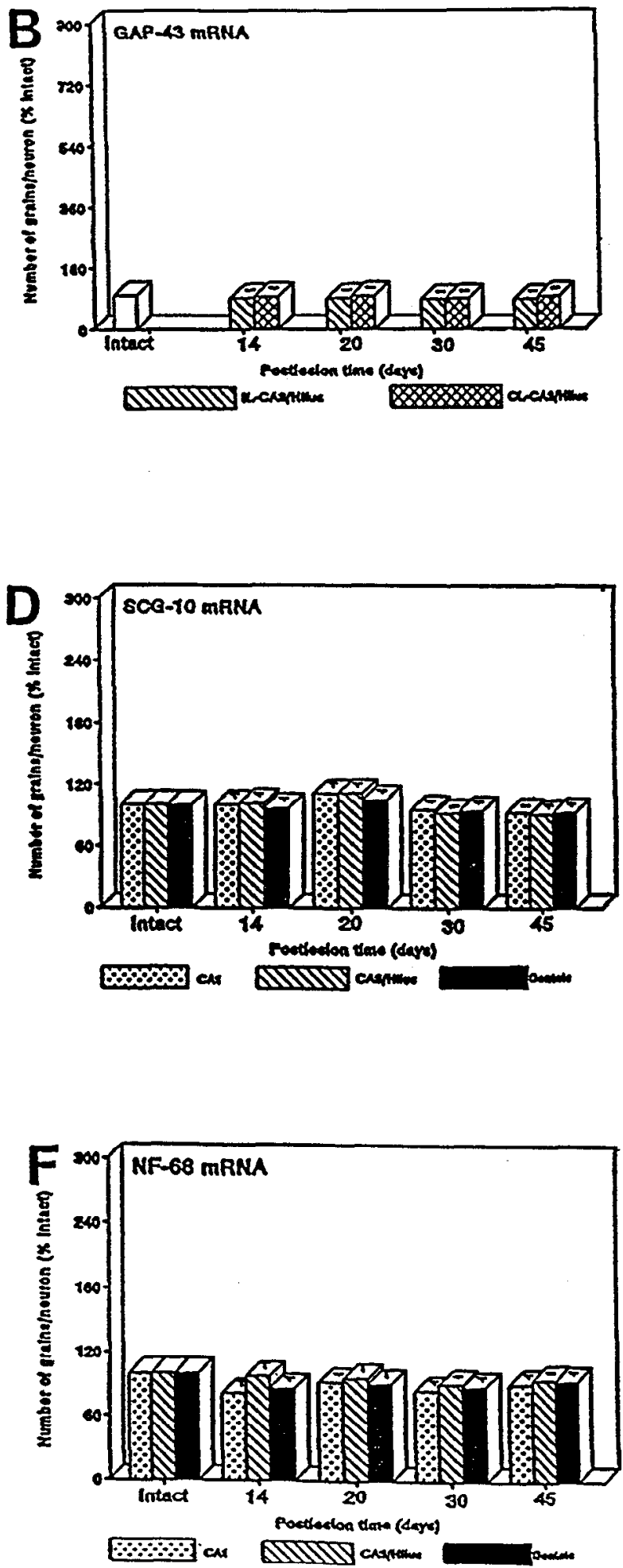

Figure 7. Quantification of GAP-43 $(A, B)$, SCG-10 $(C, D)$, and NF-68 $(E, F)$ mRNA expression in septohippocampal portions of the hippocampal formation following an $\mathrm{EC} / \mathrm{FF}$ lesion in young and aged rats. Data are given as percentage of grain number per neuronal ccll body found in intact animals. Values represent means \pm SEM. 
contralateral hippocampus between 6 and $15 \mathrm{~d}$ following an EC lesion, a time when sprouting from C/A axons occurs (Lin et al., 1992). Our finding that following an EC/FF lesion in young rats, GAP-43 mRNA was significantly increased in hilar and CA3 neurons of the C/A pathway provides further support that GAP-43 is important in the regulation of neurite outgrowth in the hippocampus following brain injury and suggests that the cellular events that regulate neurite outgrowth in the adult brain are a recapitulation of the developmental process. In contrast, consistent with a dampened sprouting response in aged rats, GAP-43 was not induced in hilar or CA3 pyramidal cells following an $\mathrm{EC} / \mathrm{FF}$ lesion in aged animals suggesting that in the hippocampus factors that regulate GAP-43 mRNA expression in response to brain injury decline with age.

The finding that SCG-10 was unaltered following the combined lesion in both young and aged animals suggests that not all developmentally regulated GAPs are involved in the sprouting of $\mathrm{C} / \mathrm{A}$ axons of the hippocampus following neuronal deafferentation. SCG-10 is a growth associated protein that has been shown to be induced in neural crest cells stimulated with NGF and repressed in response to glucocorticoid administration, similar to GAP-43 (Federoff et al., 1988; Stein et al., 1988). SCG10 is also similar to GAP-43 in that both are expressed at high levels in the neonate animal, and remain at moderate levels in the adult animal within "plastic" areas of the hippocampus. Although its exact role in neurite outgrowth has not been elucidated, a previous study from our lab has found that following a unilateral cortical lesion, SCG-10 mRNA expression is upregulated in neurons of the contralateral cortex, a time when homotypic corticostriate axons from the contralateral cortex are induced to sprout and form new synaptic contacts in the deafferented striatum (McNeill et al., 1992). The authors suggest that while GAP proteins are part of a general cellular cascade of morphological and molecular events involved in reactive synaptogenesis, the induction of specific GAP proteins may be differentially regulated in different parts of the brain based on the type of axonal outgrowth required at the lesion site (i.e., paraterminal vs collateral sprouting). It is possible that in the partially deafferented hippocampus that SCG-10 may be upregulated in other remaining afferent pathways which sprout into the dentate gyrus after the $\mathrm{EC} / \mathrm{FF}$ lesion (i.e., contralateral EC). However, while this hypothesis is intriguing, further studies will be needed to confirm this hypothesis.

Our finding that NF-68 mRNA expression was unchanged following an EC/FF lesion in young or aged animals was not unexpected. NF-68 is one of the triplet neurofilament proteins which comprises the axon cytoskeleton. Although NF-68 is only one of many cytoskeletal proteins, it is a neuron-specific protein that is found in both axons and dendrites, unlike other proteins such as lubulin, which are present in both neurons and glia (Kleinman et al., 1990). Previous studies have established that neurofilaments are intrinsic determinants of axonal caliber (Hoffman and Lasek, 1980; Hoffman et al., 1987) and increased expression of NF-68 during maturation is associated with increased caliber of axons. In addition, others have shown that NF expression is downregulated during both development and regeneration within the PNS (Hoffman, 1989) where axonal caliber is decreased, as well as in some neurodegenerative diseases of the CNS (McLachlan et al., 1988; Hill et al., 1993). In general, axonal transport studies have suggested that neurofilaments are not required during the initial outgrowth of axons or dendrites, or in the formation of specific contacts (Shaw et al.,
1985), and alterations in NF-68 mRNA expression have primarily been observed following axotomy or crush injuries, not following deafferentation lesions. Our finding support this hypothesis. Our data suggest that since the EC/FF lesion does not directly injure neurons of the C/A pathway, it is unlikely that axonal shrinkage occurs.

In summary, data from our lesion experiments comparing young and aged animals suggests that the age of the animal at the time of the lesion affects neurite outgrowth of C/A axons in the dentate gyrus. Diminished plasticity in aged rats has been reported previously (Scheff et al., 1980) and may reflect a reduction in the ability of neurons to synthesize materials necessary for growth, a modification of the glial reaction, or changes in the target tissue. Previous studies have suggested that alterations in the production of factors necessary to initiate a sprouting response may change with age, however, while some studies have shown that levels of NGF mRNA and protein are decreased in aged rats (Koh and Loy, 1987; Larkfors et al., 1987), others have reported no change (Crutcher and Weingartner, 1991). In addition, levels of mRNA for brain derived neurotrophic factor (BDNF), a trophic factor known to support the survival and outgrowth of basal forebrain cholinergic neurons, and its receptors, trkB, are unchanged in the hippocampal formation during normal aging (Lapchak et al., 1993). Furthermore, it is important to note that not all regions of the brain show a similar slowing of the sprouting response in aged rats. Recent studies from our laboratory have found that dendritic recovery within the striatum (Brown et al., 1993) and expression of SCG-10 mRNA (Cheng et al., 1993) in the contralateral cortex following a unilateral cortical lesion have a similar time course in young adult and aged rats. These data suggest that alterations in trophic factors and their receptors in aged rats most likely play an important role in the regulation of neurite outgrowth in response to brain injury. However, age-related declines in the sprouting response are not consistent across all regions of the brain and may be brain region and cell-type specific.

\section{References}

Benowitz LI, Routtenberg A (1987) A membrane phosphoprotein associated with neural development, axonal regeneration, phospholipid metabolism, and synaptic plasticity. Trends Neurosci 10:527532.

Benowitz LI, Schmidt JT (1987) Activity-dependent sharpening of the regenerating retinotectal projection in goldfish: relationship to the expression of growth-associated proteins. Brain Res 417:118126.

Benowitz LI, Apostolides PJ, Perrone-Bizzozero N, Finklestein SP, Zwiers $H$ (1988) Anatomical distribution of the growth-associated protein GAP-43/B-50 in the adult rat brain. J Neurosci 8:339-352.

Benowitz LI, Rodriguez WR, Neve RL (1990) The pattern of GAP43 immunostaining changes in the rat hippocampal formation during reactive synaptogenesis. Mol Brain Res 8:17-23.

Brown SA, Cheng H-W, McNeill TH (1993) Morphometric analysis of ipsilateral and contralateral striatal neurons following a unilateral cortical lesion. Soc Neurosci Abstr 19:1716.

Caceres A, Steward O (1983) Dendritic reorganization in the denervated dentate gyrus of the rat following entorhinal cortical lesions. A Golgi and electron microscopic analysis. J Comp Neurol 214: $387-403$.

Cheng H-W, Jiang T, Mori N, McNeill TH (1993) Effect of age on the expression of SCG-10 and P-19 mRNA during reactive synaptogenesis. Soc Neurosci Abstr 19:1715.

Cimler BM, Giebelhaus DH, Wakim BT, Storm DR, Moon RT (1987) Characterization of murine cDNAs encoding P-57, a neural-specific calmodulin-binding protein. J Biol Chem 262:12158-12163.

Coleman P, Finch C, Joseph J (1990) The need for multiple time points in aging studies. Neurobiol Aging 11:1-2. 
Cotman CW, Anderson KJ (1988) Synaptic plasticity and functional stabilization in the hippocampal formation: possible role in Alzhei mer's disease. Adv Neurol 47:313-335.

Cotman CW, Nadler JV (1978) Reactive synaptogenesis in the hippocampus. In: Neuronal plasticity (Cotman CW, ed), pp 227--271. New York: Raven.

Cotman CW, Scheff SW (1979) Compensatory synapse growth in aged animals after neuronal death. Mech Ageing Dev 9:103-11\%.

Cotman CW, Nietro-Sampedro M, Harris EW (1981) Synapse replacement in the nervous system of adult vertebrates. Physiol Rev 61:684-784.

Crutcher KA, Weingartner J (1991) Hippocampal NGF levels are not reduced in the aged Fischer 344 rat. Neurobiol Aging 12:449-454.

Federoff HJ, Grabcyzk E, Fischman MC (1988) Dual regulation of GAP-43 gene expression by nerve growth factor and glucocorticoids. J Biol Chem 263:19290 19295.

Flood DG, Coleman PD (1991) The neuropil and GAP-43/B-50 in normally aging and Alzheimer's disease human brain. Prog Brain Res 89:263-269.

Forman DS, Berenberg RA (1978) Regeneration of motor axons in the rat sciatic nerve studied by labeling with axonally transported radioactive proteins. Brain Res 156:213-225.

Gall C, Lynch G (1981) Fiber architecture of the dentate gyrus following ablation of the entorhinal cortex in rats of different ages: evidence for two forms of axon sprouting in the immature brain. Neuroscience 6:903-910.

Geddes JW, Monaghan DT, Cotman CW, Lott IT, Kim RC, Chui HC (1985) Plasticity of hippocampal circuitry in Alzheimer's disease. Science 230:1179-1181.

Himi T, Okazaki T, Wang H, McNeill TH, Mori N (1994) Differential localization of SCG10 and P19/stathmin mRNAs in adult rat brain indicates distinct roles for these growth-associated proteins. Neuroscience 60:907-926.

Hoff SF, Scheff SW, Benardo LS, Cotman CW (1982a) Lesion-induced synaptogenesis in the dentate gyrus of aged rats. I. Loss and reacquisition of normal synaptic density. J Comp Neurol 204:246252.

Hoff SF, Scheff SW, Benardo LS, Cotman CW (1982h) I esion-induced synaptogenesis in the dentate gyrus of aged rats. II. Demonstration of an impaired degeneration clearing response. J Comp Neurol 204:253-259.

Hoffman PN (1989) Expression of GAP-43, a rapidly transported growth-associated protein, and class II Beta-tubulin, a slowly transported cytoskeletal protein, are coordinated in regenerating neurons. J Neurosci 9:893-897.

Hoffman PN, Lasek RJ (1980) Axonal transport of the cytoskeleton in regenerating motor neurons: constancy and change. Brain Res 202:317-333.

Hoffman PN, Cleveland DW, Griffin JW, Landes PW, Cowan NJ, Price DL (1987) Neurofilament gene expression: a major determinant of axonal caliber. Proc Natl Acad Sci USA 84:3472-3476.

Kleinman R, Banker G, Steward O (1990) Differential subcellular localization of particular mRNAs in hippocampal neurons in culture. Neuron 5:821-830.

Koh S, Loy R (1987) Age-related loss of nerve growth factor sensitivity in rat basal forebrain neurons. Brain Res 440:396-401.

Kruger L, Bendotti C, Rivolta R, Samanin R (1992) GAP-43 mRNA localization in the rat hippocampus $\mathrm{CA}_{3}$ field. Mol Brain Res 13: 267-272.

Kruger L, Bendotti C, Rivolta R, Samanin R (1993) Distribution of GAP-43 mRNA in the adult rat brain. J Comp Neurol 333:417-434.

Lapchak PA, Araujo DM, Beck KD, Finch CE, Johnson SA, Hefti F (1993) BDNF and trkB mRNA expression in the hippocampal formation of aging rats. Neurobiol Aging 14:121-126.

Larkfors L, Ebendal T, Whittemore SR, Persson H, Hoffer B, Olson L (1987) Decreased level of nerve growth factor (NGF) and its messenger RNA in the aged rat brain. Mol Brain Res 3:55-60.

Lin L-H, Bock S, Carpenter K, Rose M, Norden JJ (1992) Synthesis and transport of GAP-43 in entorhinal cortex neurons and perforant pathway during lesion-induced sprouting and reactive synaptogenesis. Mol Brain Res 14:147-153.

Linden DJ, Wong KA, Sheu F-S, Routtenberg A (1988) NMDA receptor blockade prevents the increase in protein kinase $C$ substrate (protein F1) phosphorylation produced by long-term potentiation. Brain Res 458:142-148.
Lovinger DM, Colley PA, Akers RF, Nelson RB, Routtenberg A (1986) Direct relation of long-term synaptic potentiation to phosphorylation of membrane protein $F_{1}$, a substrate for membrane protein kinase C. Brain Res 399:205-211.

Lynch G, Matthews DA, Mosko S, Parks T, Cotman CW (1972) Induced acetylcholinesterase-rich layer in dentate gyrus following entorhinal lesions. Brain Res 42:311-318.

Lynch G, Stanfield B, Cotman CW (1973) Developmental differences in post-lesion axonal growth in the hippocampus. Brain Res 59: $155-168$.

Lynch G, Gall C, Rose G, Cotman C (1976) Changes in the distribution of the dentate gyrus associational system following unilateral or bilateral entorhinal lesions in the adult rat. Brain Res 110:5771.

Lynch G, Gall C, Cotman C (1977) Temporal parameters of axon "sprouting" in the brain of the adult rat. Exp Neurol 54:179-183.

McNeill TH, Cheng H-W, Rafols JA, Mori N (1992) Neuroplasticity and Parkinson's disease. In: Progress in Parkinson's disease research (Hefti F, Weiner WJ, eds), pp 299-323. New York: Future.

Meberg PJ, Routtenberg A (1991) Selective expression of protein F1/ (GAP-43) mRNA in pyramidal but not granule cells of the hippocampus. Neuroscience 45:721-733.

Meiri KF, Pfenninger KH, Willard MB (1986) Growth-associated protein, GAP-43, a polypeptide that is induced when neurons extend axons, is a component of growth cones and corresponds to pp46, a major polypeptide of a subcellular fraction enriched in growth cones. Proc Natl Acad Sci US 1 83:3537-3541.

Nadler JV, Cotman CW, Paoletti C, Lynch GS (1977) Histochemical evidence of altered development of cholinergic fibers in the rat dentate gyrus following lesions. J Comp Neurol 171:589-604.

Nairn AC, Shenolikar S (1992) The role of protein phosphatases in synaptic transmission, plasticity and neuronal development. Curr Opinion Neurobiol 2:296-301.

Nielander HB, Schrama LH, van Rozen AJ, Kasperaitis M, Iestreicher AB, deGraan PNE, Gispen P, Schotma WH (1987) Primary structure of the neuron-specific phosphoprotein B-50 is identical to growth-associated protein GAP-43. Neurosci Res Commun 1:163172.

Paxinos G, Watson C, eds (1986) The rat brain in stereotaxic coordinates. San Diego: Academic.

Represa A, Duyckaerts C, Tremblay E, Hauw JT, Ben-Ari Y (1988) Is senile dementia of the Alzheimer type associated with hippocampal plasticity? Brain Res 457:355-359.

Rosenthal A, Chan SY, Henzel W, Haskell C, Kuang W-J, Chen JN, Wilcox A, Ullrich DV, Goeddel E, Routtenberg A (1987) Primary structure and mRNA localization of protein F1, a growth-related protein kinase $\mathrm{C}$ substrate associated with synaptic plasticity. EMBO J 6:3641-3646.

Schauwecker PE, McNeill TH (1995) Fnhanced but delayed axonal sprouting of the commissural/associational pathway following a combined entorhinal cortex/fimbria fornix lesion. J Comp Neurol 351:1-12.

Scheff SW, Dekosky ST (1983) Steroid suppression of axon sprouting in the hippocampal dentate gyrus of the adult rat: dose-response relationship. Exp Neurol 82:183-191.

Scheff SW, Bernardo LS, Cotman CW (1978) Decrease in adrenergic axon sprouting in the senescent rat. Science 202:775-778.

Scheff SW, Bernardo LS, Cotman CW (1980) Decline in reactive fiber growth in the dentate gyrus of aged rats compared to young adult rats following entorhinal cortex removal. Brain Res 199:2138.

Shaw G, Weber K (1985) Differential expression of neurofilament triplet proteins in brain development. Nature 298:277-279.

Sheehan DC, Hrapchak BB (1980) The Holmes stain. In: Theory and practice of histotechnology (Sheehan DC, Hrapchak BB, eds), pp 256-257. St. Louis: Mosby.

Skene JH (1989) Axonal growth-associated proteins. Annu Rev Neurosci $12: 127-156$.

Skene JHP, Willard M (1981) Changes in axonally transported proteins during axon regeneration in tad retinal ganglion cells. J Cell Biol 89:86-95.

Stein R, Orit S, Anderson DJ (1988) The induction of a neural-specific gene, SCG10, by nerve growth factor in PC12 cells is transcriptional, protein synthesis dependent, and glucocorticoid inhibitable. Dev Biol 127:316-325. 
Stewart HJS, Jessen KR, Mirsky R (1993) After TGF- $\beta$ treatment GAP-43 is localized to the Golgi area of the schwann cell. Soc Neurosci Abstr 19:879.

Van der Zee CEEM, Nielander HB, Vos JP, da Silva SL, Verhaagen J, Oestreicher AB, Schrama LH, Schotman P, Gispen WH (1989) Expression of growth-associated protein B-50 (GAP43) in dorsal root ganglia and sciatic nerve during regenerative sprouting. J Neurosci 9:3505-3512.

Van Hooff COM, De Graan PNE, Oestricher AB, Gispen WH (1988) B-50 phosphorylation and polyphosphoinositide metabolism in nerve growth cone membrane. J Neurosci 8:1789-1795. 